\title{
MO SIGNAL IN CO-PT AND CO-PD ALLOY DISKS: COMPARISON TO RESPECTIVE MULTILAYERS AND TBFECO
}

\author{
D. WELLER, J. HURST, H. NOTARYS, H. BRÄNDLE1), \\ R.F.C. FARROW, R. MARKS, G. HARP \\ IBM Research Division, Almaden Research Center, San Jose,CA 95120, USA \\ 1)present address: \\ Balzers AG, FL-9496 Balzers, Fürstentum Liechtenstein
}

\begin{abstract}
A wavelength dependent, quantitative comparison of the static magneto-optical signal in Co-Pt and Co-Pd alloys, $\mathrm{Co} / \mathrm{Pt}$ and $\mathrm{Co} / \mathrm{Pd}$ multilayers and $\mathrm{TbFeCo}$ has been carried out. Dynamic testing of evaporated $\mathrm{Co}-\mathrm{Pt}$ and Co-Pd alloys, embedded in quadrilayer structures has been demonstrated at $488 \mathrm{~nm}$. Large mark CNR ratios above $60 \mathrm{~dB}$ in $\mathrm{Co}-\mathrm{Pt}$ alloys were found on ungrooved glass disks.
\end{abstract}

KEYWORDS: MO RECORDING IN CO-PT AND CO-PD ALLOYS, MAGNETO-OPTICAL SPECTROSCOPY

\section{INTRODUCTION}

$\mathrm{Co} / \mathrm{Pt}$ and $\mathrm{Co} / \mathrm{Pd}$ multilayers show MO signal advantages at short wavelengths compared with $\mathrm{TbFeCo}$ or GdTbFe, which are currently used in $\mathrm{MO}$ recording products [1-3]. In the case of $\mathrm{Co} / \mathrm{Pt}$ $\mathrm{a} \simeq 3 \mathrm{~dB}$ performance improvement has been demonstrated in dynamic testing at wavelengths of $488 \mathrm{~nm}$ [4] and $458 \mathrm{~nm}$ [5]. This was attributed to the larger Kerr effect of these materials at short wavelengths.

Respective Co-Pt and Co-Pd alloy systems have been suggested recently for MO recording $[6,7]$, as they promise even better performance compared to their multilayer counterparts. Lin et al. [8], Weller et al. [6], and Farrow et al. [9] showed, that evaporated $\mathrm{Co}_{\sim 30} \mathrm{Pt}_{\sim 70}$ alloys can indeed fulfill all the necessary prerequisites for MO recording. Key to establishing perpendicular magnetic anisotropy and suitable coercivities in Co-Pt is an elevated deposition temperature in the range $200-300^{\circ} \mathrm{C}$ and a $\mathrm{Pt}$ content near 70 at $\%$. The latter also controls the Curie temperature, which is chosen near $250^{\circ} \mathrm{C}$ for MO recording films. We mention, that the present alloys are different from those reported in 1975 by Treves et al.[10], who investigated the tetragonally distorted $\mathrm{Co}-\mathrm{Pt} \mathrm{Ll}_{0}$ phase near the $\mathrm{Co}_{50} \mathrm{Pt}_{50}$ composition. Tsunashima et al. [11] and Hashimoto et al. [2] already in 1989 reported evaporated and sputtered Co-Pd alloys with perpendicular magnetic anisotropy, which they attributed to strain in conjunction with large negative mangetostriction coefficients. Hashimoto et al.[2] also reported that respective sputtered Co-Pt alloys were in-plane. Carcia and Zeper [12] for the first time in 1990 mentioned the possibility of perpendicular magnetic anisotropy in high Ar pressure deposited alloy like "multilayers".

In this paper, we focus on a quantitative signal comparison of $\mathrm{Co}-\mathrm{Pt}$ and $\mathrm{Co}-\mathrm{Pd} \mathrm{MO}$ recording disks in the wavelength range $1580-245 \mathrm{~nm}(0.8-5 \mathrm{eV}$ photon energy) and compare the results to TbFeCo. Thermomagnetic writing in $\mathrm{Co}_{\sim 30} \mathrm{Pt}_{\sim 70}$ and $\mathrm{Co}_{\sim 30} \mathrm{Pd}_{\sim 70}$ alloys is demonstrated for the first time.

\section{EXPERIMENTAL}

The present alloys and multilayers were evaporated in $\mathrm{HV}$ at substrate temperatures of $\sim 50^{\circ} \mathrm{C}$ and $200-250^{\circ} \mathrm{C}$, respectively, on differently buffered substrates [6]. Both thick single films $(d>100 \mathrm{~nm})$ and quadrilayer disks were investigated with an automated Kerr spectrometer [13]. The disks were made on $5.25^{\prime \prime}$-diameter flat glass substrates in quadrilayer structures of the type D1/MO/D2/R. The dielectric layers $D 1$ and $D 2$ are reactively rf-diode sputtered $\operatorname{SiN}_{x}$ films and the reflector layer $R$ is dcmagnetron sputtered Al. These layers were kept unchanged in the present comparison. For the active MO layer optimized films of CoPt, CoPd and $\mathrm{TbFeCo}$ were chosen. $\mathrm{Co} / \mathrm{Pt}$ multilayers, $\mathrm{Co}-\mathrm{Pt}$ alloys and $\mathrm{Co}-\mathrm{Pd}$ alloys were evaporated in $\mathrm{HV}$ and $\mathrm{Co} / \mathrm{Pd}$ multilayers were deposited by sputtering. Additionally, MBE grown Co-Pt alloy films were investigated, as they showed a considerably higher coercivity $(>4 \mathrm{kOe})$ than the respective $\mathrm{HV}$ deposited Co-Pt alloys [9]. The compositions and thickness ratios - in the case of multilayers - were determined with X-ray diffraction and X-ray fluorescence. Dynamic testing experiments were performed at $488 \mathrm{~nm}$ with a system described by Hurst et al. [14].

\section{RESULTS AND DISCUSSION}

We define the static MO signal as the product of the disk reflectivity $\mathrm{R}$ and the complex Kerr effect $|\Phi|=\left(\theta_{\mathrm{K}}{ }^{2}+\varepsilon_{\mathrm{K}}\right)^{2 / 1 / 2}$. This can be measured by separately determining the reflectivity $R$, the Kerr ro- 


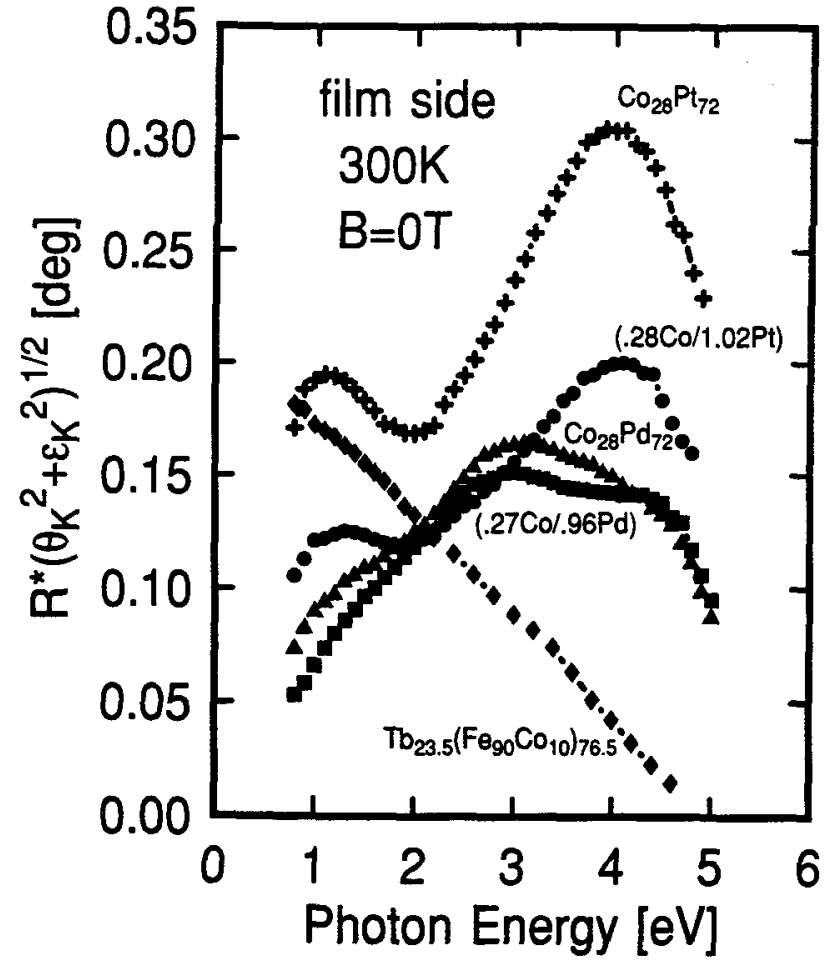

Fig.1: Static MO signal $R \times\left(\theta_{K}{ }^{2}+\varepsilon_{K}^{2}\right)^{1 / 2}$ of $(\geq 100 \mathrm{~nm})$ thick Co-Pd and Co-Pt alloys, $\mathrm{Co} / \mathrm{Pt}$ and $\mathrm{Co} / \mathrm{Pd}$ multilayers and $\mathrm{TbFeCo}$ as function of the photon energy $(0.8-5 \mathrm{eV})$. The compositions are indicated in the figure.

tation $\theta_{\mathrm{K}}$ and the Kerr ellipticity $\varepsilon_{\mathrm{K}}$. Fig.1 shows a static signal comparison of several at least $100 \mathrm{~nm}$ thick films, measured in remanence from the air side in the range $0.8-5.0 \mathrm{eV}$. It is important to include $\varepsilon_{\mathrm{K}}$ in the signal evaluation, as this can contribute considerably, especially in the case of the present alloys. The compositions and thickness ratios, as indicated in the figure, were chosen such, that large perpendicular magnetic anisotropies $\left(\mathrm{K}_{\mathrm{u}} \sim 0.5 \mathrm{MJ} / \mathrm{m}^{3}\right)$ and suitable Curie temperatures $\left(200-300^{\circ} \mathrm{C}\right)$ for MO recording were obtained. As a result of this quantitative comparison we conclude that a considerable signal enhancement at short wavelengths $\lambda \leq 600 \mathrm{~nm}$ $(\mathrm{E}>2 \mathrm{eV})$ can be expected in all of the investigated films. This is attributed to extra Kerr contributions from (via exchange interaction with Co) spin-polarized $\mathrm{Pt}$ and $\mathrm{Pd}$ bands in these systems. These give rise to the strong uv peaks at $4.0 \mathrm{eV}$ and $3.0 \mathrm{eV}$ in Fig.l for the $\mathrm{Pt}$ and $\mathrm{Pd}$ systems, respectively. This latter point has recently been confirmed by ab-initio band structure and MO calculations by Sticht [15]. The larger Kerr effect of alloys as compared to multilayers is due to enhanced exchange in these systems $[16,17]$. The largest enhancement with respect to $\mathrm{Tb}_{23.5}\left(\mathrm{Fe}_{90} \mathrm{Co}_{10}\right)_{76.5}$ is found in the $\mathrm{Co}_{28} \mathrm{Pt}_{72}$ alloy, which outperforms the other materials in view in the whole wavelength range, except in the far IR. At $428 \mathrm{~nm}$, which is the wavelength of a possible compact blue laser source [18], the enhancement amounts to a factor of $2.4(7.5 \mathrm{~dB})$ in

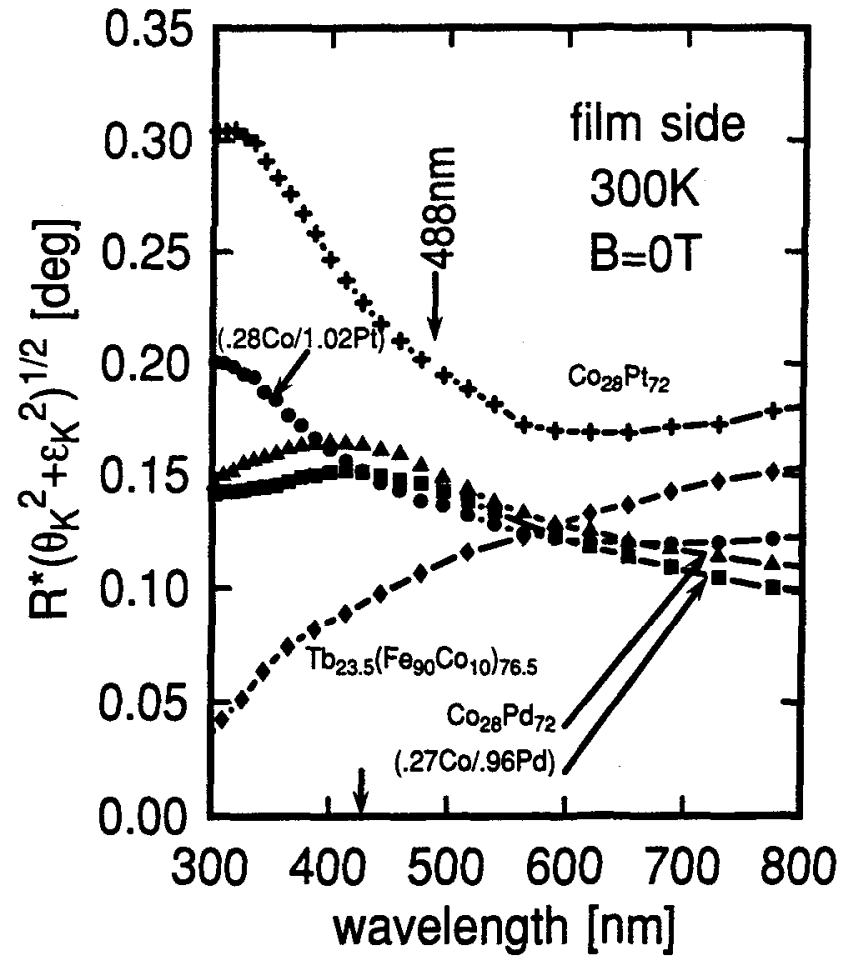

Fig.2: As Fig.1 but as function of the wavelength $(300-800 \mathrm{~nm})$. All measurements were made at room temperature and in remanence from the film/air side.

$\mathrm{Co}_{28} \mathrm{Pt}_{72}$, while $\mathrm{Co} / \mathrm{Pt}$ multilayers and $\mathrm{Co} / \mathrm{Pd}$ multilayers and alloys show smaller but still considerable enhancement factors of $\simeq 1.7(4.6 \mathrm{~dB})$ at that wavelength. This is best seen in an expanded plot in Fig.2, where we have plotted the MO signal as function of the wavelength in the range $300-800 \mathrm{~nm}$. Table 1 summarizes gain factors at $488 \mathrm{~nm}$ and $428 \mathrm{~nm}$ compared to $\mathrm{TbFeCo}$. Note however, that these gain factors refer to single (thick) films only. The measured Kerr rotation and ellipticity data of the present Co-Pt alloy films together with ellipsometrically determined optical constants $\mathrm{n}$ and $\mathrm{k}$ were

Tab. 1: Experimentally determined MO signal gain factors at $488 \mathrm{~nm}$ and $428 \mathrm{~nm}$ for thick single films of different recording candidate materials: $\mathrm{Co}_{28} \mathrm{Pt}_{72}$ and $\mathrm{CO}_{28} \mathrm{Pd}_{72}$ alloys and $77 \mathrm{x}(0.28 \mathrm{Co} / 1.02 \mathrm{Pt})$ and $77 \mathrm{x}(0.27 \mathrm{Co} / 0.96 \mathrm{Pt})$ multilayers [nm] (gain factor $\left.\mathrm{G}=\mathrm{S}_{\mathrm{MO}} / \mathrm{S}_{\mathrm{TbFe} \mathrm{Co}_{0}}\right)$.

\begin{tabular}{ccccc}
\hline MO & $\begin{array}{c}\mathrm{G} \\
\lambda=488 \mathrm{log}(\mathrm{G})\end{array}$ & $\begin{array}{c}\mathrm{G} \\
\lambda=428 \mathrm{~nm}\end{array}$ \\
\hline $\mathrm{Co}-\mathrm{Pt}$ & 1.73 & $4.8 \mathrm{~dB}$ & 2.40 & $7.5 \mathrm{~dB}$ \\
$\mathrm{Co}-\mathrm{Pd}$ & 1.46 & $3.3 \mathrm{~dB}$ & 1.82 & $5.2 \mathrm{~dB}$ \\
$\mathrm{Co} / \mathrm{Pd}$ & 1.38 & $2.8 \mathrm{~dB}$ & 1.68 & $4.5 \mathrm{~dB}$ \\
$\mathrm{Co} / \mathrm{Pt}$ & 1.31 & $2.3 \mathrm{~dB}$ & 1.68 & $4.5 \mathrm{~dB}$ \\
\hline
\end{tabular}


used as input data for optical stack-design calculations. As a result of these calculations we made quadrilayers glass/D1/MO/D2/R for operation at $488 \mathrm{~nm}$ with $\mathrm{Dl}=40 \mathrm{~nm}, \mathrm{MO}=20 \mathrm{~nm}, \mathrm{D} 2=20 \mathrm{~nm}$ and $\mathrm{R}=50 \mathrm{~nm}$. D2 was chosen to be relatively thin and constitutes a compromise between optimal optical and thermal stacking. These parameters were kept constant for the following comparison of static and dynamic test results. Fig. 3 shows the static MO signal data of the best performing quadrilayer disks made of the above materials. The measurements were carried out from the substrate side. The trends are similar to those in Fig.2, however the onset of optical absorption in glass near $400 \mathrm{~nm}$ causes the reflectivity and therefore the signal to drop off below about 370nm. Note, that there are no distinct peak features in the signal spectra, which are clearly observed in the separate Kerr effect and reflectivity spectra, showing that $R$ and $|\Phi|$ are essentially inversely related.

Table 2 lists the quadrilayer gain factors at $488 \mathrm{~nm}$, compared to $\mathrm{TbFeCo}$ and in addition contains large mark $(\sim 5 \mu \mathrm{m})$ CNR measurements obtained at $488 \mathrm{~nm}$ with $2 \mathrm{~mW}$ read power, $30 \mathrm{kHz}$ bandwidth and a disk velocity of $10 \mathrm{~m} / \mathrm{s}$. Co-Pd alloys have not been included in this comparison so far, as we were not yet able to fabricate respective high coercivity alloy films without using metallic buffers (see e.g. $[6,8]$ ). On a Co-Pd alloy based quadrilayer disk, we could nevertheless demonstrate write/read capability and have so far achieved a large mark CNR of 51dB. A $40 \AA$ thick Pd buffer was used and the coercivity of that disk was $\sim 8000$ e.

Tab. 2: Experimentally determined MO signal gain factors at $488 \mathrm{~nm}$ of quadrilayers $(\mathrm{Dl}=40 \mathrm{~nm}$, $\mathrm{D} 2=20 \mathrm{~nm}, \quad \mathrm{MO}=20 \mathrm{~nm}, \quad \mathrm{R}=50 \mathrm{~nm}) \quad$ with $\mathrm{MO}=\mathrm{Co} / \mathrm{Pt}$ multilayers, $\mathrm{Co} / \mathrm{Pd}$ multilayers and Co-Pt alloys. (Definitions as in TableI) Large mark CNR ratios $(2 \mathrm{~mW}$ read power, $1 \mathrm{MHz}$ signal frequency, $10 \mathrm{~m} / \mathrm{s}$ linear velocity)

\begin{tabular}{cccc}
\hline MO & G $\begin{array}{c}20 \log (\mathrm{G}) \\
\lambda=488 \mathrm{~nm}\end{array}$ & $\mathrm{CNR}$ \\
& & \\
\hline $\mathrm{Co} / \mathrm{Pt}$ & 1.36 & $2.6 \mathrm{~dB}$ & $63.5 \mathrm{~dB}$ \\
$\mathrm{Co} / \mathrm{Pd}$ & 0.91 & $-0.8 \mathrm{~dB}$ & $59.0 \mathrm{~dB}$ \\
$\mathrm{Co}-\mathrm{Pt}$ & 1.64 & $4.3 \mathrm{~dB}$ & $61.7 \mathrm{~dB}$ \\
$(\mathrm{Co}-\mathrm{Pd}$ & $\cdots . .$. & $\ldots . .--$ & $51.0 \mathrm{~dB})$
\end{tabular}

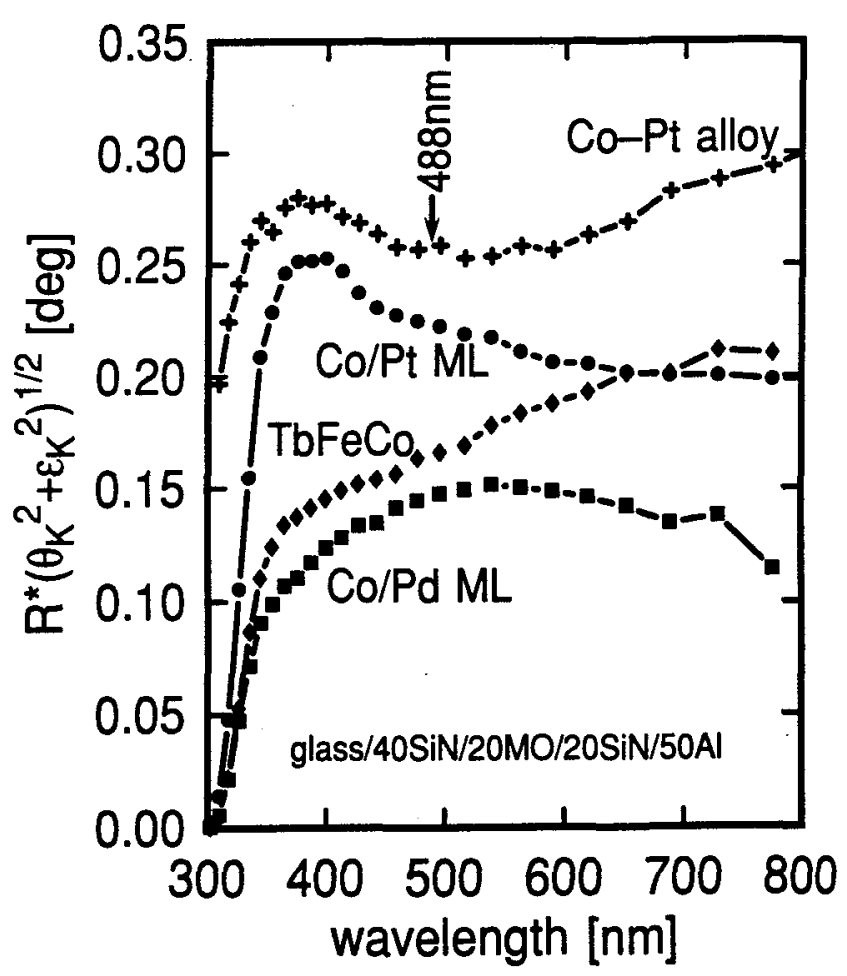

Fig.3: Static MO signal of quadrilayers (thicknesses in $\mathrm{nm}$ ) vs wavelength measured in remanence through the glass substrate.

\section{CONCLUSIONS}

High performance $\mathrm{Co} / \mathrm{Pt}$ and $\mathrm{Co} / \mathrm{Pd}$ multilayer and (MBE grown) Co-Pt alloy based disks with large mark CNR ratios exceeding $59 \mathrm{~dB}$ on flat glass disks have been demonstrated. CNR scales roughly with the static MO signal. Inferior performance of the Co-Pt alloy disks is attributed to extra write noise.

\section{ACKNOWLEDGEMENT}

The authors would like $G$. Gorman and $R$. Swope for numerous $\mathrm{X}$-ray diffraction and $\mathrm{X}$-ray fluorescence and J.C. Scott for optical constants measurements.

\section{REFERENCES}

[1] W.B. Zeper, F.J.A.M. Greidanus, P.F. Carcia, C.R. Fincher, "Perpendicular magnetic anisotropy and magneto-optical Kerr effect of vapor-deposited Co/Pt layered structures," $J$. Appl. Phys., vol. 65, 1989, pp. 4971-4975.

[2] S. Hashimoto, Y. Ochiai, K. Aso, Jpn. J. Appl. Phys., vol. 28, 1989, pp. L1824-1826. 
[3] C.-J. Lin, H.V. Do, "Magneto-optical recording on evaporated $\mathrm{Co} / \mathrm{Pt}$ multilayer films," IEEE Trans. Magn., vol. 26, 1990, pp. 17001702.

[4] S. Hashimoto, A. Maesaka, Y. Ochiai, "Recording on $\mathrm{Co} / \mathrm{Pt}$ magneto-optical disks using a 488-nm wavelenght laser," J. Appl. Phys., vol. 70, 1991, pp. 5133-5135.

[5] W.B. Zeper, A.P.J. Jongenelis, B.A.J. Jacobs, H.W. van Kesteren, "Magneto-optical recording in $\mathrm{Co} / \mathrm{Pt}$ multilayer and GdTbFe-based disks at 820, 647 and 458-nm wavelength," IEEE Trans. Mag., vol. 28, 1992, pp. 2503-2505.

[6] D. Weller, H. Brändle, G. Gorman, C.-J. Lin and H. Notarys, "Magnetic and magneto-optical properties of Cobalt Platinum alloys with perpendicular magnetic anisotropy," Appl. Phys. Lett., vol. 61, 1992, p. 2726.

[7] D. Weller, H. Brändle, C. Chappert, "Relationship between Kerr effect and perpendicular magnetic anisotropy in Co-Pt and Co-Pd alloys," Symp. Mag. Ultrathin Films, Multilayers and Surfaces Lyon, Sept. 1992, J. Magn. Magn. Mater. (accepted), 1993.

[8] C.-J. Lin, G. Gorman, "Evaporated CoPt alloy films with strong perpendicular magnetic anisotropy," Appl. Phys. Lett., vol. 61, 1992, p. 1600.

[9] R.F.C. Farrow, R.H. Geiss, G.L. Gorman, G. Harp, R.F. Marks and E.E. Marinero, "Large Perpendicular Anisotropy, High Coercivity Co-Pt Alloys For Magneto-Optical Re- cording," MORIS'92, Tucson, AZ, December 7-9, 1992.

[10] D. Treves, J.T. Jacobs, E. Sawatzky, J. Appl. Phys., vol. 46, 1975, pp. 2760-2765.

[11] S. Tsunashima, K. Nagase, K. Nakamura, S. Uchiyama, "Perpendicular Magnetic Anisotropy of Pd-Co Alloy Films And Related Multilayers," IEEE Trans. Magn., vol. 25, 1989, pp. 3761-3763.

[12] P.F. Carcia and W.B. Zeper, "Sputtered $\mathrm{Pt} / \mathrm{Co}$ Multilayers for Magneto-Optical Recording," IEEE Trans. Magn., vol. 26, 1990, pp. 1703-1705.

[13] H. Brändle, D. Weller, S.S.P. Parkin, J.C. Scott, and P. Fumagalli, W. Reim, R.J. Gambino, R. Ruf, G. Güntherodt, "Magneto-optical properties of $\mathrm{CrO}_{2}$," Phys. Rev. B, vol. 46, 1992, pp. 13889-13895.

[14] J. Hurst, D. Weller, H. Notarys, MORIS'92, Tucson, AZ, December 7-9, 1992.

[15] J. Sticht (private communication), 1992.

[16] D. Weller, W. Reim, K. Spörl and H. Brändle, "Spectroscopy of multilayers for magneto-optic storage," J. Magn. Magn. Mater., vol. 93, 1991, pp. 183-193.

[17] H. Brändle, D. Weller, S.S.P. Parkin, J.C. Scott, C.-J. Lin, "Optical and Magneto-Optical Characterization of Evaporated $\mathrm{Co} / \mathrm{Pt} \mathrm{Al-}$ loys and Multilayers," IEEE Trans. Mag., vol. 28, 1992, pp. 2967-2969.

[18] W. Kozlovsky, W. Lenth, E.E. Latta, A. Moser, J.L. Bona, Appl. Phys. Lett., vol. 56, 1990, p. 2291. 